\title{
AISLAMIENTO DE LACTOBACILLUS NATIVOS DE PRODUCTOS DE FERMENTACIÓN EN LA CIUDAD DE TACNA
}

\section{RESUMEN}

En la presente investigación se aisló Lactobacilos usando el medio de cultivo agar rogosa, adecuado para el aislamiento de lactobacilos a partir de productos fermentados como: yogurt, queso y leche. Los lactobacilos son muy exigentes a los requerimientos nutritivos, creciendo en forma anaerobia y microaerófila, en una atmósfera con $\mathrm{Co}_{2}$.

Las colonias crecieron, pequeñas, cremosas, casi transparentes, de $1 \mathrm{~mm}$ de diámetro, células Grampositivas y no presentan la enzima catalasa, llegándose a determinar Lactobacillus casei, L. acidophilus y L. bulgaricus.

\section{INTRODUCCIÓN}

El conocimiento de las especies de Lactobacillus nativos en Tacna es poco y quizá nulo, sin embargo, se conocen sus propiedades o ventajas nutritivas en el consumo de productos fermentados mediante bacterias lácticas que forman parte del conjunto de microorganismos que contribuyen en su fermentación, como son los productos lácteos. Este proyecto de investigación permitirá conocer especies de Lactobacillus nativos que se encuentran dentro de las fermentaciones formando parte de un conjunto de microorganismos que realizan dicha fermentación.

Las bacterias lácticas como es el género Lactobacillus estan comprendidas por bacterias en forma bacilar de $0,5-1,2 \times 1,0-$ 10,0 um; comúnmente se asocian en cadenas cortas, son anaerobias facultativas o microaerófilas, catalasa y citocromo negativos (Foo etal., 1993). Excepcionalmente pueden poseer motilidad por flagelos peritricos. Los I a ctobacilos son autótrofos quimioorganotróficos, necesitan medios complejos para su crecimiento, degradan la sacarosa para producir lactato. La temperatura óptima de crecimiento de los lactobacilos está entre $30-40{ }^{\circ} \mathrm{C}$ (Foo etal., 1993; Morishita etal., 1981). Su hábitat natural es variado, pudiéndolos encontrar en el aparato gastrointestinal de mamíferos y aves, incluyen alimentos de origen vegetal y animal (Callon et al., 2004; Holt et al., 1998).

La flora ácido láctica ha sido tema de muchos estudios por analistas de la leche a niveles diferentes de propiedades como son: probióticas, contribuyendo a la digestibilidad de la lactosa e hidrolizar sales biliares; anticarcinogenos presentan actividades antagónicas además de potenciar la respuesta inmune. Estos efectos positivos son consecuencia de la interacción de bacterias prebióticas e intestino que además pueden deberse a varios factores según sea la bacteria.

Cuando se habla de flora ácido-láctica, se refiere a la gran diversidad de microorganismos presentes en la lactosa, que son capaces de producir ácidos, ya sean perjudiciales para el producto o beneficioso para el mismo.

El ácido láctico existe como indicios en la leche fresca, con un porcentaje medio de 30 $\mathrm{mg} / \mathrm{l}$. Es, ante todo, el resultado de la fermentación láctica y, según estudiaremos más adelante, dentro de la industria láctea puede presentar un carácter beneficioso o perjudicial.

Dentro de los lactobacilos tenemos: termófilos, que se desarrollan de manera normal a temperatura de $45^{\circ} \mathrm{C}$ y los mesófilos que son menos resistentes a temperaturas 
extremas, su desarrollo ideal se da a $30^{\circ} \mathrm{C}$. A temperaturas por encima de $40^{\circ} \mathrm{C}$, no se desarrollan. El lactobacilo o bacteria del ácido láctico es un género de bacterias Gram positivas anaerobias, denominadas asi debido a que la mayoria de sus miembros convierte lactosa y otros monosacáridos en ácido láctico. Normalmente son benignas e incluso necesarias, habitan en el cuerpo humano y en el de otros animales; por ejemplo, están presentes en el tracto gastrointestinal y en la vagina. Muchas especies son importantes en la descomposición de material vegetal. La producción de ácido láctico hace que su ambiente sea ácido, lo cual inhibe el crecimiento de bacterias dañinas. Algunas especies de Lactobacillus son usadas industrialmente para la producción de yogur y otros alimentos fermentados. Algunas bebidas de yogur contienen Lactobacillus como suplemento dietético. Muchos lactobacilos son los únicos seres vivos que no requieren hierro para vivir y tienen una tolerancia extremadamente alta al peróxido de hidrógeno.

Muchos lactobacilos operan usando un metabolismo homofermentativo (es decir, sólo producen ácido láctico a partir de azúcares) y son aerotolerantes a pesar de la ausencia de cadena respiratoria. Esta aerotolerancia es dependiente del manganeso y ha sido estudiada y explicada en Lactobacillus plantarum. La fermentación láctica se refiere al proceso celular por el cual los microorganismos como los lactobacilos, utilizan la glucosa para obtención de energía y donde el producto de desecho es el ácido láctico.

Este proceso lo realizan muchas bacterias (Ilamadas bacterias lácticas), algunos protozoos y ocurre en los tejidos animales, en ciertos protozoarios, hongos y bacterias. Un ejemplo de este tipo de fermentación es la acidificación de la leche. Ciertas bacterias (lactobacilos), al desarrollarse en la boca, utilizan la lactosa (azúcar de leche) como fuente de energía. La lactosa, al fermentar, produce energia que es aprovechada por las bacterias y el ácido láctico es eliminado. La coagulación de la leche (cuajada) resulta de la precipitación de las proteínas de la leche, y ocurre por el descenso de $\mathrm{pH}$ debido a la presencia de ácido láctico. En ausencia de oxígeno, las células animales convierten el ácido pirúvico en ácido láctico. El ácido láctico puede ser un veneno celular. Cuando se acumula en las células musculares produce sintomas asociados con la fatiga muscular. El ácido láctico tiene excelentes propiedades conservantes de los alimentos.

Los lactobacilos producen sustancias inhibitorias contra microorganismos indeseables, lo que permite una mayor preservación natural del producto. El aislamiento de cepas con propiedades metabólicas idóneas para la formulación de cultivos iniciadores para una fermentación controlada científicamente, en particular especies de lactobacillus productoras de sustancias antimicrobianas y tolerantes al etanol, se convierten, por lo tanto, en una alternativa viable para el desarrollo de un producto inocuo de alta calidad que pueda cumplir con los estándares más exigentes.

El ácido láctico se produce mediante la fermentación láctica. En condiciones de ausencia de oxígeno (anaerobias), la fermentación responde a la necesidad de la célula de generar la molécula de $\mathrm{NAD}+$, que ha sido consumida en el proceso energético de la glucólisis. En la glucólisis la célula transforma y oxida la glucosa en un compuesto de tres átomos de carbono, el ácido pirúvico, obteniendo dos moléculas de ATP; sin embargo, en este proceso se emplean dos moléculas de NAD+ que actúan como aceptores de electrones y pasan a la forma NADH. Para que puedan tener lugar las reacciones de la glucólisis que producen energía es necesario restablecer el NAD+ por otra reacción. Los dos tipos de fermentación que se ilustran aquí son particularmente importantes, ya que sus subproductos -ácido láctico en el primer caso y etanol en el segundo- son utilizados en la industria alimentaria. La fermentación láctica también se verifica en el tejido muscular cuando, a causa de una intensa actividad motora, no se produce una aportación adecuada de oxígeno que permita el desarrollo de la respiración celular.

El ácido láctico (del lat. lac, lactis, leche), también conocido por su nomenclatura oficial ácido 2-hidroxi-propanoico o ácido a-hidroxipropanoico, es un compuesto químico que juega importantes roles en diversos procesos bioquímicos, como la fermentación láctica. Es un ácido carboxílico, con un grupo hidroxilo en el carbono adyacente al grupo carboxilo lo que lo convierte en un ácido ahidroxílico (AHA) de fórmula $\mathrm{H} 3 \mathrm{C}-\mathrm{CH}(\mathrm{OH})$ $\mathrm{COOH}$. En solución puede perder el protón y convertirse en el anión lactato.

Desde la década pasada la investigación científica mundial ha centrado su atención en la búsqueda de preservantes naturales de origen microbiano para la alimentación humana. Como consecuencia de las investigaciones se ha propuesto la incorporación de cultivos iniciadores, principalmente de bacterias lácticas productoras de compuestos antimicrobianos 
en la conservación de la calidad sanitaria de algunos alimentos (Ohmomo etal., 2003).

Los cultivos lácticos con las caracteristicas de interés industrial mencionadas pueden ser usados como cultivos iniciadores, constituyendo una estrategia de prevención del establecimiento de bacterias patógenas y contaminantes de alimentos.

La leche fermentada en general, y más concretamente el yogur, tiene la propiedad de contener microorganismos vivos que les confieren cualidades organolépticas y nutricionales. Estos productos se consideran probióticos, ya que al ingerirse en ciertas cantidades ejercen efectos beneficiosos para la salud (Schaafsma 1996a, 1996b). Las bacterias lácticas consideradas como probióticos son entre otras Bifidobacterium spp., Lactobacillus acidophilus y Lactobacillus casei.

Los efectos de los lactobacilos sobre la salud son muy variados; se puede destacar el mantenimiento de la flora intestinal, mejora de la digestión de la lactosa, actividad inmunomodulante, actividad anticancerigena y reducción de los niveles de colesterol (Sanders 1993; Tannock 1999).

Pero la presencia de bacterias lácticas vivas exige que se respeten algunos imperativos de conservación y de fecha de caducidad, para garantizar a los consumidores todos los beneficios. Se ha sugerido que para que las bacterias lácticas ejerzan su acción como probióticos deben llegar al intestino vivas y en una cantidad suficiente $(106-107 \mathrm{cel} / \mathrm{ml})$ para que se puedan apreciar sus efectos y consigan adherirse, implantarse o multiplicarse en el tracto intestinal (Kurmann y Rasic 1991; Bouhnik 1993). Por todo ello es de especial interés mantener la viabilidad de las bacterias lácticas (Anonymous 1998).

Los lactobacilos, según los productos de fermentación de azúcar, se dividen en dos grupos. El grupo homofermentativo es el mayor y convierte casi completamente el azúcar fermentado en ácido láctico; el grupo heterofermentativo está constituido por formas que producen cantidades importantes de otros productos de fermentación, incluyendo dióxido de carbono, etanol y ácido acético.

En tanto el estudio de aglutinógenos es complicado, por la neta tendencia de lactobacilos a la aglutinación espontánea en solución salina, entre los lactobacilos heterofermentativos son demostrable diez diferentes aglutinógenos, junto con algunos antígenos menores compartidos junto con la especie Leuconostoc.

De las diferentes especies de lactobacilos diferenciables por reacciones fisiológicas, solo tres mencionamos.

Lactobacillus acidophilus. Este organismo, cultivado por primera vez por Moro en 1900, a partir de heces de lactante, ha sido aislado del intestino de casi todos los mamiferos, muchos otros vertebrados y algunos invertebrados. Su cantidad aumenta en el intestino cuando aumenta el contenido de carbohidratos en la dieta; pueden ser predominantes cuando se ingiere una dieta láctea. Estos bacilos, bastante gruesos y de longitud variable, se disponen aislados, a pares frecuentemente algo flexionados en la unión, y en empalizadas. Las cadenas largas, las formas filamentosas y las formas en masa no son raras. Los cultivos jóvenes se tiñen uniformemente grampositivos; los cultivos viejos, a menudo, muestran coloración listada o bipolar y pueden decolorarse fácilmente. Las colonias, generalmente pequeñas, pueden variar en su forma: de la opaca, redonda y lisa a la aplanada, translúcida e irregular, frecuentemente con aspecto de cristal. Las reacciones de fermentación son variables, pero la mayor parte de cepas producen ácido pero no gas, a partir de glucosa, lactosa, maltosa y sacarosa y coagulan la leche en 48 horas. El bacilo de Döderlein (1892), miembro común de la flora vaginal, que se cree ayuda a las defensas naturales contra la infección por contribuir a la acidez de las secreciones vaginales, parece ser idéntico a $L$. Acidophilus.

Lactobacillus bulgaricus. Este nombre se asignó a un organismo aislado por Grigoroff, en 1905, de leche búlgara fermentada. Ganó importancia por los trabajos de Metchnikoff, quien, como antes se dijo, creia que la putrefacción intestinal podía reprimirse bebiendo leche fermentada por este microorganismo. Cuando más tarde se demostró que L. Bulgaricus no se implantaba en el intestino, se empleó en terapéutica experimental, se inclinó a favor de $L$. Acidophilus. Es más difícil de cultivar que éste, ligeramente más voluminoso y algo diferente en la fermentación de azúcares; sin embargo, se relacionan estrechamente. Se ha señalado que $L$. Bulgaricus raramente se desarrolla a 15 ${ }^{\circ} \mathrm{C}$, muere en cultivos repetidos en caldo de lactosa - peptona - levadura, es incapaz de desarrollarse en medio que contenga 2,5 por 100 de cloruro de sodio y no crece en caldo a $\mathrm{pH}$ de 7,8 , en tanto que $L$. acidophilus puede crecer en todas estas condiciones. El bacilo de Boas - Oppler, visto por primera vez en 1895 en jugo gástrico de pacientes con carcinoma 
gástrico, es miembro de este grupo, semejante, si no idéntico, a L. Bulgaricus.

Lactobacillus delbrueckii Beijerinck. Estos bacilos tienen un tamaño de $0,5-0,8 \times 2,7$ um y se presentan aislados, en parejas o en cadenas. Cuando aparecen en parejas, ambos bacilos forman, con frecuencia, un ángulo obtuso. La temperatura óptima es de unos 45 ${ }^{\circ} \mathrm{C}$, la máxima de $52{ }^{\circ} \mathrm{C}$ y la mínima de $21-34$ ${ }^{\circ} \mathrm{C}$; pero estas temperaturas varian mucho en las diversas cepas.

Las colonias son de bordes enteros, y el ácido láctico formado es levógiro. La bacteria no fermenta la lactosa, pero, por término medio, la sacarosa y la maltosa. Debido a no disponer de la habilidad de fermentar la lactosa, esta bacteria no puede crecer en leche.

Los mejores substratos liquidos para $L$. Delbrueckii son: macerado de cebada con carbonato cálcico precipitado (substrato nutritivo número 27), mosto dulce, de cocción de germen de malta o substrato $Y$ con glucosa. Los substratos sólidos más idóneos son el agar de Blickfeldt con carbonato cálcico precipitado (substrato nutritivo número 20 ) o substrato $Y$ con glucosa. El autolizado de levadura es favorable en todo para el crecimiento y la acidogénesis de esta bacteria.

L. Delbrueckii se encuentra en la naturaleza en las partes vegetales, sobre todo en los cereales. En la industria fermentativa se utiliza en gran escala para la acidificación de mosto y malta.

La bacteria se presenta en muchas variedades con diversos grados de acidificación y con diversas temperaturas óptimas para el crecimiento.

Un cultivo puro de L. Delbrueckii se puede obtener a partir de cebada u otro cereal, con arreglo al método de enriquecimiento, de la forma siguiente: el cereal molturado se riega con agua, añadiéndose un poco de malta dulce. Esta mezcla se tiene a $45^{\circ} \mathrm{C}$ durante 2 a 5 días. Cuando después de este periodo no se observe formación de película y el líquido que se encuentra por encima de las partes maceradas sólidas tenga un enturbiamiento sedoso, con toda probabilidad se ha desarrollado $L$. Delbrueckii en la iniciación, y entonces se intentará obtener un cultivo puro en el agar de Blickfeldt en carbonato cálcico precipitado, eventualmente después de la revivificación en macerado estéril.

Las especies siguientes del género Lactobacillus pertenecen al tipo de lactobacterias que se llaman estreptobacterias, porque, por lo común, aparecen en cadenas largas. Los bacilos aislados son, con frecuencia, bastante cortos, y la articulación se puede percibir mejor en la preparación coloreada. Estas bacterias estaban reunidas antes en un género independiente, Streptobacterium Orla-Jensen.

Estas bacterias no solo se diferencian desde el punto de vista morfológico de las especies del género Lactobacillus mencionadas hasta aqui, sino también con respecto a las temperaturas de crecimiento y las exigencias en substratos nutritivos.

Lactobacillus casei Holland. Son bacilos cortos en cadenas cortas o largas. Su temperatura óptima, $30^{\circ} \mathrm{C}$; máxima, $37-40$ ${ }^{\circ} \mathrm{C}$, en algunos casos incluso hasta $45^{\circ} \mathrm{C}$; mínima, $10^{\circ} \mathrm{C}$. Las colonias presentan bordes enteros, y el ácido láctico formado es dextrógiro, con frecuencia con algún vestigio de ácido láctico levógiro. Esta especie puede formar hasta un $1,5 \%$ de ácido en leche, pero, debido al crecimiento bastante lento de la bacteria, solo coagula leche después de 3 a 5 días. Medra bien en substratos $C$ y en $C+Y$. De los disacáridos prefiere la lactosa. En ausencia de azúcar puede utilizar los lactatos como fuente de carbono. L. Casei contiene muchas endoenzimas, que después de la muerte de la bacteria atacan la caseina y la pueden degradar en combinaciones solubles. Por esta razón juega un papel importante en la maduración del queso.

Lactobacillus plantarum Holland. Los bacilos miden $0,8-1,0 \times 3-8$ um y se encuentran aislados o en cadenas cortas. La temperatura óptima es de $34-37^{\circ} \mathrm{C}$. Por regla general, esta especie produce ácido láctico racémico. Esta bacteria se encuentra, con frecuencia, en la naturaleza, sobre todo en las partes vegetales. Participa en la acidificación espontánea de muchos productos agrícolas

Lactobacillus brevis Bergey etal. Bacilos cortos con extremos redondeados, asemejándose, a veces, a estreptococos, que se presentan aislados o en cadenas cortas, aunque en ocasiones en filamentos largos. La acidogénesis es heterofermentativa, y el ácido láctico formado es racémico. La acidogénesis está ligada a una ligera producción de anhidrido carbónico, Temperatura óptima 30 ${ }^{\circ} \mathrm{C}$; máxima $37^{\circ} \mathrm{C}$, y mínima $15^{\circ} \mathrm{C}$.

Esta bacteria se encuentra en la leche, quesos, granos de kefir, en partes vegetales, en choucrout en fermentación, en pastas ácidas de levaduras y también en muchos lugares de la naturaleza, sobre todo alli donde la fruta, tal como tomates y similares, inicia la putrefacción.

El objetivo del presente estudio es el aislamiento de lactobacillus nativos a partir de productos fermentados en la ciudad de Tacna con la finalidaa de contar con cepas con características fermentadoras para su 
posterior uso. Para lo cual se trazaron los siguientes objetivos especificos: Recolectar productos fermentados artesanalmente; aislar bacterias a partir de productos fermentados; identificar las bacterias (Lactobacillus) y conservarlas en ceparios.

\section{MATERIALYMÉTODOS}

La fuente de obtención de bacterias de Lactobacillus fue a partir de productos fermentados en la industria de productos lácteos, como ser: queso, leche y yogurt. Se sembraron en placas Petri (por la técnica de agotamiento y estriado) con medios de cultivo de agar rogosa para lactobacilos. Los cultivos se incubaron en estufa a una temperatura de $37^{\circ} \mathrm{C}$ durante 24 horas en anaerobiosis con un ambiente de $\mathrm{CO}_{2}$.

Después de este tiempo, se reconocieron y se aislaron las colonias con características propias de las bacterias lácticas (Lactobacillus). A estas colonias aisladas se les hizo una coloración diferencial de Gram y una identificación bioquímica con el reactivo de peróxido de hidrogeno para verificar la producción de la enzima catalasa u otra enzima capaz de degradar este $\mathrm{H}_{2} \mathrm{O}_{2}$.

Al mismo tiempo se sometieron a las pruebas de crecimiento y desarrollo de estos microorganismos a las temperaturas de $15^{\circ} \mathrm{C}$ y $45{ }^{\circ} \mathrm{C}$ y a los medios de cultivo con concentraciones de $\mathrm{NaCl}$ de $4 \%$.

Las bacterias de Lactobacillus identificadas se almacenaron en un cepario (en tubos de ensayo que contenian el medio de cultivo de agar rogoso) debidamente rotuladas, que luego de su crecimiento en los mencionados tubos de vidrio se llevaron a refrigerar a $4^{\circ}$ para su conservación.

\section{RESULTADOS Y DISCUSIONN}

Todas las muestras presentaron colonias características de Lactobacillus, luego que los cultivos se incubaran en estufa a una temperatura de $37^{\circ} \mathrm{C}$ durante 24 horas en anaerobiosis con un ambiente de $\mathrm{CO}_{2}$; sin embargo, en las muestras de queso hubo un mejor desarrollo de las colonias, las cuales crecieron en la superficie del agar rogoso muy pequeñas de color cremosa, casi transparentes, de aproximadamente $1 \mathrm{~mm}$ de diámetro, propias de Lactobacillus.

A estas colonias aisladas en las placas Petri se les hizo una coloración diferencial de Gram y una identificación bioquímica con el reactivo de peróxido de hidrógeno para verificar la producción de la enzima catalasa u otra enzima capaz de degradar este $\mathrm{H}_{2} \mathrm{O}_{2}$. Dando como resultado las colonias como bacilos grampositivos y además en las placas se observaron presencia de levaduras. En cuanto a la prueba con el peróxido de hidrógeno se evidenció por observación que no había desprendimiento de gas al entrar en contacto con las colonias de bacterias.

En cuanto al crecimiento de las bacterias lácticas o lactobacilos a diferentes temperaturas y a una elevada concentración de $\mathrm{NaCl}$, se obtuvieron los siguientes resultados: a temperaturas de $45^{\circ} \mathrm{C}$ se desarrollaron las bacterias de $L$. acidophilus y L. bulgaricus mientras que a la concentración de $4 \%$ de $\mathrm{NaCl}$, la bacteria que dio un desarrollo positivo fue $L$. casei. $Y$ para diferenciar las bacterias que crecieron a temperaturas de $45^{\circ} \mathrm{C}$ se llevó a un medio de cultivo que contenia como única fuente de carbono a la sucrosa y dando como crecimiento o desarrollo positivo para $L$. Acidophilus.

Las bacterias que se determinaron como: L. acidophilus, L. bulgaricus y $L$. casei se almacenaron en un cepario (luego de su crecimiento en tubos de ensayo que contenian el medio de cultivo de agar rogoso) debidamente rotulados, se llevaron a refrigerar a $4^{\circ} \mathrm{C}$ para su conservación.

\section{IV.CONCLUSIONES}

1.Se aislaron bacterias de $L$. acidophilus, $L$. bulgaricus y $L$. casei a partir de productos de fermentación como son queso, yogurt y leche

2.Como microorganismos acompañantes de la fermentación se determinaron a las células de levaduras.

3.El mejor crecimiento de Lactobacillus fue en un ambiente anaeróbico con presencia de $\mathrm{Co}_{2}$.

\section{RECOMENDACIONES}

Realizar estudios hasta determinar con el complejo comportamiento con las demás especies en un mismo fermentador con la finalidad de determinar la importancia de cada uno de los microorganismos presentes en la fermentación.

Realizar investigaciones previas para la aplicación de especies de Lactobacillus del presente trabajo como cultivos iniciadores en productos fermentados. 
Continuar la investigación de cepas de Lactobacillus enfocándolo desde el punto de vista como productoras de sustancias inhibitorias de contaminación bacteriana acompañante de muchas fermentaciones.

\section{BIBLIOGRAFÍA}

Anonymous. (1998). Cultured products of tomorrow. Dairy Foods. 8:46.

Bergey's Manual Of Systematic Bacteriology. (1984). N. Krieg Eds. Vol. 1-2. Baltimore. Williams and Wilkins.

De Man, J., Rogosa, M., Sharpe, E. (1960). A medium for the cultivation of lactobacilli. J. Appl. Bacteriol. 23: 130-155.

David A. A. Mossel, B. M. (2003). Microbiologia de los alimentos. Fundamentos ecológicos para garantizar y comprobar la integridad (inocuidad y calidad) microbiológica de los alimentos. 724 pág.

Moreno, Y. y col. Aplicación de fluorocromos para el estudio de la viabilidad de las Bacterias Ácido Lácticas (BAL) presentes en productos lácteos. Departamento de Biotecnología, Universidad Politécnica de Valencia, Camino de Vera, 14, 46002, Valencia.

Quillama, E., Liendo, N. (1995). "Aislamiento e identificación de bacterias lácticas asociadas a Chicha de Jora". Boletín de Lima $N^{\circ} 100$. Vol. XVII.Pp: 171-180.

Quillama, E. (1998). Producción de bacteriocinas por cepas de Lactobacillus aisladas de chicha de jora. Tesis para optar al grado académico de Magíster en Microbiología. Facultad de Farmacia y Bioquímica. UNMSM.

Prescott, L.M.; Harley, J.p. \& Klein, D.A.. (2004). Microbiología. Quinta edicion. 1272 pg. España.

Schaafsma G. (1996 a). Significance of probiotics in human diets. In SOMED 21st International Congress on microbial ecology and disease. Paris, October 28-30, 1996. Paris: Institut Pasteur, p. 38.

Schaafsma G. (1996 b). State of the art concerning probiotic strains in milk products. IDF Nutr. NewsI. 5: 23-24.Madigan, M. Martinko J. (1988). Brock bilogia de los alimentos. Prentice halllberia. Madrid

Sanders M.e. (1993). Effect of consumption of lactic cultures on human health. In J. Kinsella (ed.), Advances in food and nutrition research. Academic Press, San Diego, California. Pp.67130.
Yousef A. E Carlstrom C.(2006). Microbiología de los alimentos. Manual de laboratorio. 320 págs.

\section{ANEXO}

Cuadro 1: Características de crecimiento de especies de Lactobacillus en diferentes medios de cultivo y temperatura

\begin{tabular}{|c|c|c|c|c|c|c|c|c|c|c|}
\hline \multirow{2}{*}{ Mictroorganiemo } & \multicolumn{2}{|c|}{ Crecimiento o } & \multicolumn{6}{|c|}{ Acidode } & \multirow{2}{*}{$\begin{array}{l}\text { NH, } \\
\text { arginina }\end{array}$} & \multirow{2}{*}{$\begin{array}{l}\text { Creclmiento ea } \\
\text { Caldo } 4 \% \mathrm{NaCa}\end{array}$} \\
\hline & $15^{\circ} \mathrm{C}$ & $45^{\circ} \mathrm{C}$ & b & $=$ & at & ma & ж & si & & \\
\hline Lacidophitho & $\cdot$ & + & + & + & + & . & - & . & - & - \\
\hline L. bulgaricas & - & + & + & . & . & - & - & - & - & - \\
\hline L courei & + & $\mathrm{v}$ & $+\%$ & H. & + & + & + & - & . & + \\
\hline L plantarum & + & $\mathrm{v}$ & + & + & + & + & . & . & . & + \\
\hline L delibrackifif & - & + & - & + & - & - & - & . & - & - \\
\hline$\angle$ lecichmani & - & + & $*-$ & + & + & . & . & . & \%० & - \\
\hline L. brois & + & - & $+1-$ & + & to & +1- & - & + & + & + \\
\hline L. fermenti & - & + & + & to & - & - & - & + & + & - \\
\hline
\end{tabular}

+ Sí hay crecimiento bacteriano;

- No hay crecimiento bacteriano y

$\checkmark$ el crecimiento bacteriano es variable

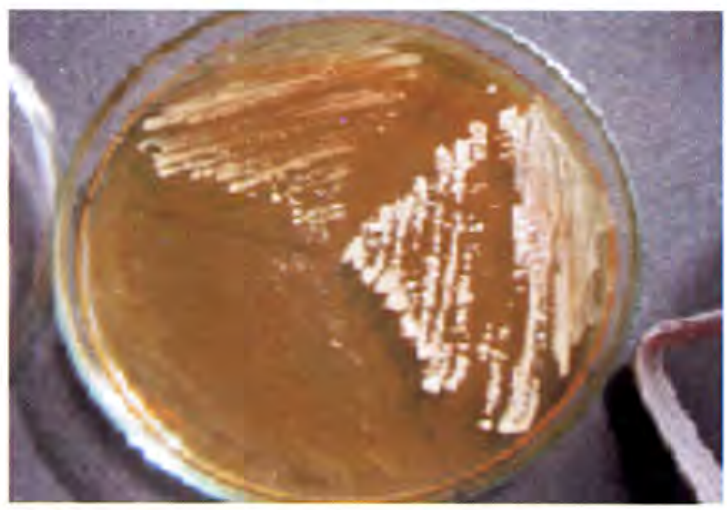

Figura 1: Caracteristicas del crecimiento en colonias de Lactobacillus en agar rogoso.

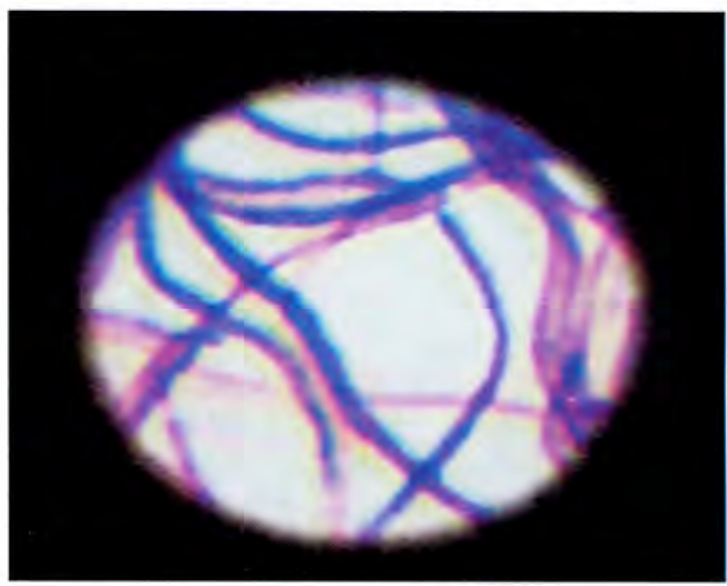

Figura 2: Observación en el microscopio con objetivo 100X de células de Lactobacillus. 